\title{
Currently Known Characteristics of Bat Species Represented in Hamburg in Respect of Wind Turbine Casualties
}

\author{
Polina Krapivnitckaia ${ }^{1}$, Veit Dominik Kunz ${ }^{2}$, Carolin Floeter ${ }^{3}$ \\ ${ }^{1}$ CC4E/Energy Campus, Hamburg University of Applied Sciences, Germany, ${ }^{2}$ Department of \\ Process Engineering, Hamburg University of Applied Sciences, Germany, ${ }^{3}$ Department of \\ Environmental Engineering, Hamburg University of Applied Sciences, Germany
}

\begin{abstract}
Bats are animals protected by the law, however many become wind turbine related casualties. To estimate the risk from wind turbines, a systematic literature research has been conducted. A total of 6 groups of bat characteristics have been chosen as relevant for the risk estimation: body dimensions, flight height, flight style and speed, foraging space and distance, response to light, and acoustical characteristics of bat calls. Their values have been presented in this paper for the 7 bat species that are represented in the wind park near Hamburg, Germany. Analyzing the values of the known bat characteristics, conclusions about the species with high collision risk possibility have been drawn. However, these conclusions have not always been supported by the statistics of carcass findings at wind parks across Germany, which raises questions, for instance about the degree of influence of certain characteristics above others, and indicates a need for further research.
\end{abstract}

Keywords: bat casualties; bat characteristics; wind turbines. 


\section{Introduction}

According to the German Federal Law of Nature Protection (Bundesnaturschutzgesetz), bats belong to the category of endangered animals and are particularly protected - it is forbidden to catch, injure or kill them. However, Hochradel et al. (2015) have proven that bats are attracted by wind turbines, and Brinkmann et al. (2011) have estimated that on average 9.5 bats are killed per wind turbine in the period from July to September in Germany.

With the idea of reducing $\mathrm{CO}_{2}$ emissions and backing out of nuclear energy, Germany is actively increasing the share of renewable energy in its total generation mix. A total of 29248 onshore wind turbines with a cumulative capacity of $53.2 \mathrm{GW}$ were operating in Germany by 30.06.2019 (Deutsche WindGuard GmbH 2019). Thus, the increasing number of wind turbines raises a concern for the bat population.

\section{Bats and Wind Turbines}

To estimate the risk from wind turbines on different bat species, a systematic literature research has been conducted and several bat characteristics have been selected. In this section, bat species represented in the study area, relevance of the selected bat characteristics and their values, as well as the wind turbine parameters of the study area are discussed.

\subsection{Bat Species Represented in Hamburg}

There are about 1400 bat species worldwide, of which 25 are represented in Germany (Nature Conservation Directive of the European Union). With the help of acoustical detectors, 7 species were identified in the area of an onshore wind park near Hamburg, Germany, during risk assessment studies in the planning phase (Reimers 2015): Serotine bat (Eptesicus serotinus), Daubenton's bat (Myotis daubentonii), Common noctule (Nyctalus noctula), Nathusius's pipistrelle (Pipistrellus nathusii), Common pipistrelle (Pipistrellus pipistrellus), Soprano pipistrelle (Pipistrellus pygmaeus), Brown long-eared bat (Plecotus auritus).

\subsection{Relevant Bat Characteristics in Respect of Wind Turbine Casualties}

To facilitate data gathering and comparison of different species, 6 groups of bat characteristics have been chosen: body dimensions (body mass, body length, wingspan), flight height (typical height and prediction rate of the bat to fly at heights), flight style and speed, foraging space and distance, response to light, and acoustical characteristics of bat calls (frequency range and intensity).

Bat body dimensions can give a general idea about the size of the carcasses in the event of bat casualties and their distribution possibilities. Comparing a rotor area altitude of a wind turbine with a typical flight height of a bat species, can identify potential conflict and highrisk zones. In the context of "shutdown-on-demand", typical flight speed of bat species can 
be used to approximate the minimal required distance to detect a bat from the operating wind turbine. Additionally, comparing a typical flight speed of a bat species with a linear speed of a blade at a certain point, one can comprehend the probability for a bat flying in the vicinity of a moving blade to evade it. Preferred foraging habitat by a bat species can to a certain degree predict its presence or absence in a wind park. Maximal foraging distance from a roost could help to estimate the probability of bat species activity near wind turbines, given that the roost locations are known. Bats vision and response to different wavelengths of light are also considered here as relevant, because obstruction lighting of wind turbines can attract or repel some bat species to the turbines.

Frequency range and volume of bat calls are characteristics that limit the acoustic detection distance of bats. Depending on these factors and the settings of the acoustical detector installed in the nacelle of a wind turbine, the detection range can vary greatly, e.g. from $70 \mathrm{~m}$ to $10 \mathrm{~m}$ (Simon et al. 2015) and less. Often, shut-down algorithms of wind turbines are based on the measured acoustic activity at the nacelle.

Bats are known to be active under certain weather conditions. However, the meteorological parameters are out of the scope of this paper, because they influence bats presence at wind turbines only temporarily. Migration of bat species is not considered for the same reason.

\subsection{Known Bat Characteristics in Respect of Wind Turbine Casualties}

The species that are represented in the wind park near Hamburg, typically have a head to body length of $35-80 \mathrm{~mm}$, a wingspan of $190-400 \mathrm{~mm}$ and a weight of 3 - $30 \mathrm{~g}$ (Dietz and Kiefer 2014; Bat Conservation Trust 2008).

According to Dietz and Kiefer (2014), E. serotinus bat species typically fly at $10-15 \mathrm{~m}$ altitudes; for $M$. daubentonii bat species that is $1-5 \mathrm{~m}$, and for $P$. nathusii is $3-10 \mathrm{~m}$. Seibert et al. (2013) recorded P. pipistrellus species at $0.5-4.5 \mathrm{~m}$ altitudes. Herrchen \& Schmitt (2018) name similar values for the flight altitude of the above-mentioned species, and specify the typical flight height of $15 \mathrm{~m}$ and more for $N$. noctula, $3-6 \mathrm{~m}$ for $P$. pygmaeus, and $3-15 \mathrm{~m}$ for $P$. auritus.

Based on recorded data, Roemer et al. (2017) have predicted the rate of the time bat species spent at higher altitudes, and for the bat species represented in the wind park, the maximum value of $42.7 \%$ is for N. noctula and minimum of $0.3 \%$ is for small Myotis group, to which M. daubentonii belongs.

Dietz and Kiefer (2014) describe flight styles of $N$. noctula and P. nathusii as fast and linear, $P$. pygmaeus as utterly agile, E. serotinus as slow. As for $M$. daubentonii, P. pipistrellus and $P$. auritus, their flight styles are agile and fast, agile and twisty, agile and slow respectively. Average speed of travel is $5 \mathrm{~m} / \mathrm{s}$ for M. daubentonii (Middleton 2006), more than $14 \mathrm{~m} / \mathrm{s}$ for N. noctula (Dietz and Kiefer 2014) and 4-6 m/s for P. pipistrellus (Seibert et al. 2013). 
Following the classifications of Denzinger and Schnitzler (2013) and of Roemer et al. (2017), $N$. noctula use open foraging spaces, while $P$. nathusii, $P$. pipistrellus and $P$. pygmaeus use edge foraging spaces, and P. auritus - narrow foraging spaces; E. serotinus and $M$. daubentonii species can use a combination of foraging spaces, open and edge, and edge and narrow respectively. As for the foraging distance, the two extreme examples are $N$. noctula and P. auritus. While one species can fly up to $25 \mathrm{~km}$ from the roost, the other typically stay within $0.5-2 \mathrm{~km}$ from the roost (Dietz and Kiefer 2014).

Similar to other characteristics, response to different wavelengths of light is species specific. As red and white lights are used in Germany for wind turbines illumination, only the behavior towards them is considered in this paper. Spoelstra et al. (2017) found no influence of red light on Plecotus and Myotis species activity and a reduction of it in white light; for Nyctalus and Eptesicus species, no effect of red or white light on bat activity was observed; Pipistrellus species were observed to be more active in white light and with no change in activity in red light. However migratory bats study by Voigt et al. (2018) revealed that P. pygmaeus and with a less extend $P$. nathusii species increased their activity in red light.

For the bat species represented in the wind park, frequency range of calls varied within $17-85 \mathrm{kHz}$ (Dietz and Kiefer 2014). The calls intensity measured at $1 \mathrm{~m}$ distance for open space aerial foragers, to which belongs $N$. noctula, is $104-111 \mathrm{~dB}$ SPL; calls intensity for edge space aerial foragers, to which one could allocate $P$. nathusii, $P$. pipistrellus and P. pygmaeus, is $101-107 \mathrm{~dB}$ SPL; for $M$. daubentonii typical call intensity is $120 \mathrm{~dB}$ SPL (Denzinger and Schnitzler 2013). P. auritus is often described in literature as a quiet or whispering bat, but no explicit values for the call intensities are given.

A summary of the above-mentioned characteristics for bats represented in the wind park near Hamburg is given in the Table 1.

\subsection{Wind turbines characteristics}

To put things into perspective, the average configuration of new turbines which are being installed in Germany are 3.3 MW nominal power, $133 \mathrm{~m}$ hub height and $122 \mathrm{~m}$ rotor diameter (Deutsche WindGuard GmbH 2019).

The wind park near Hamburg consists of 5 wind turbines with the nominal power of $2.4 \mathrm{MW}$ and 3.0 MW, hub height of $120 \mathrm{~m}$, rotor diameter of $117 \mathrm{~m}$, operational rotational speed in the range of about $7.5-14.1$ RPM. The linear speed of the blade tip can vary from 46 to $86 \mathrm{~m} / \mathrm{s}$, and the lowest point of the blade tip is $61.5 \mathrm{~m}$ above ground. The wind park area is covered dominantly with arable land and grassland with a few ditches, so that wind turbines are located in an open space. 
Table 1. Characteristics of bat species represented in the wind park near Hamburg

\begin{tabular}{|c|c|c|c|c|c|c|c|}
\hline Characteristics & $\begin{array}{c}\text { Serotine } \\
\text { bat } \\
\text { (Eptesicus } \\
\text { serotinus) }\end{array}$ & $\begin{array}{c}\text { Daubenton's } \\
\text { bat } \\
\text { (Myotis } \\
\text { daubentonii) }\end{array}$ & $\begin{array}{c}\text { Common } \\
\text { noctule } \\
\text { (Nyctalus } \\
\text { noctula) }\end{array}$ & $\begin{array}{l}\text { Nathusius's } \\
\text { pipistrelle } \\
\text { (Pipistrellus } \\
\text { nathusii) }\end{array}$ & $\begin{array}{l}\text { Common } \\
\text { pipistrelle } \\
\text { (Pipistrellus } \\
\text { pipistrellus) }\end{array}$ & $\begin{array}{c}\text { Soprano } \\
\text { pipistrelle } \\
\text { (Pipistrellus } \\
\text { pygmaeus) }\end{array}$ & $\begin{array}{c}\text { Brown long } \\
\text { eared bat } \\
\text { (Plecotus } \\
\text { auritus) }\end{array}$ \\
\hline Body mass & $18-25 \mathrm{~g}$ & $6-10 \mathrm{~g}$ & $21-30 \mathrm{~g}$ & $6-10 \mathrm{~g}$ & $3-7 \mathrm{~g}$ & $4-7 \mathrm{~g}$ & $6-9 \mathrm{~g}$ \\
\hline Body length & $58-80 \mathrm{~mm}$ & $45-55 \mathrm{~mm}$ & $37-48 \mathrm{~mm}$ & $46-55 \mathrm{~mm}$ & $35-45 \mathrm{~mm}$ & $35-45 \mathrm{~mm}$ & $37-52 \mathrm{~mm}$ \\
\hline Wingspan & $320-380 \mathrm{~mm}$ & $240-275 \mathrm{~mm}$ & $320-400 \mathrm{~mm}$ & $228-250 \mathrm{~mm}$ & $200-235 \mathrm{~mm}$ & $190-230 \mathrm{~mm}$ & $230-285 \mathrm{~mm}$ \\
\hline Flight height & $5-15 \mathrm{~m}$ & $1-6 m$ & $>15 \mathrm{~m}$ & $3-20 m$ & $0.5-6 \mathrm{~m}$ & $3-6 m$ & $3-15 \mathrm{~m}$ \\
\hline Predicted rate & $12.7 \%$ & $0.3 \%$ & $42.7 \%$ & $26.7 \%$ & $11.3 \%$ & $4.5 \%$ & $0.5 \%$ \\
\hline Flight style & Slow & fast\&agile & fast\&linear & fast\&linear & agile\&twisty & utterly agile & slow\&agile \\
\hline Speed of travel & - & $5 \mathrm{~m} / \mathrm{s}$ & $>14 \mathrm{~m} / \mathrm{s}$ & - & $4-6 \mathrm{~m} / \mathrm{s}$ & - & - \\
\hline Foraging space & open/edge & edge/narrow & open & edge & edge & edge & narrow \\
\hline Foraging distance & $4.5 \mathrm{~km}$ & $2.3-3.7 \mathrm{~km}$ & $<25 \mathrm{~km}$ & $<6.5 \mathrm{~km}$ & $1.5 \mathrm{~km}$ & $1.7 \mathrm{~km}$ & $0.5-2 \mathrm{~km}$ \\
\hline $\begin{array}{l}\text { Activity at:-red } \\
\text {-white light }\end{array}$ & $\begin{array}{l}\text { retained } \\
\text { retained }\end{array}$ & $\begin{array}{l}\text { retained } \\
\text { reduced }\end{array}$ & $\begin{array}{l}\text { retained } \\
\text { retained }\end{array}$ & $\begin{array}{c}\text { retained/increased } \\
\text { increased }\end{array}$ & $\begin{array}{c}\text { retained } \\
\text { increased }\end{array}$ & $\begin{array}{c}\text { retained/increased } \\
\text { increased }\end{array}$ & $\begin{array}{l}\text { retained } \\
\text { reduced }\end{array}$ \\
\hline Frequency range & $22-26 \mathrm{kHz}$ & $26-85 \mathrm{kHz}$ & $17-21 \mathrm{kHz}$ & $35-40 \mathrm{kHz}$ & $41-46 \mathrm{kHz}$ & $50-57 \mathrm{kHz}$ & $24-55 \mathrm{kHz}$ \\
\hline Intensity at $1 \mathrm{~m}$ & - & 100dB SPL & 104-111dB SPL & 101-107dB SPL & 101-107dB SPL & 101-107dB SPL & - \\
\hline
\end{tabular}

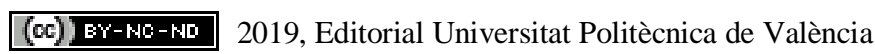




\section{Discussion}

During the conducted literature research, it has been revealed, that the information about body dimensions, typical flight height, flight style, preferred foraging spaces and typical foraging distances from roosts for different bat species is very accessible. Speed of travel or flight speed of different bat species are not very accessible, which is probably due to the agile flight styles of the most bats species in wind park near Hamburg. Bats vision and their response to light is a relatively new research topic, and few studies are published yet, so the information might be refined in the future. Although information about frequency range of calls for different bat species is widely accessible, information about intensity of these calls is not very conclusive, which is probably due to the complexity of the needed setup for a study.

When comparing the data gathered in Table 1 with the description of the wind park, the $N$. noctula species stands out. Due to typically high flight altitudes and preference of an open space for foraging, the habitat of this species highly overlaps with the rotor area of the wind turbines. This indicates a high collision risk possibility, and Dürr (2019) demonstrates that carcasses of $N$. noctula are the most frequently found and registered in Germany with $32.24 \%$ share. The other two species to stand out are P. nathusii and E. serotinus. Flying typically lower than $N$. noctula and preferring more edge space for foraging, the carcasses finding share is $28.76 \%$ for P. nathusii and $1.71 \%$ for E. serotinus (Dürr 2019). $P$. pipistrellus and $P$. pygmaeus seem also to have similar characteristics, but their finding share is $19.05 \%$ and $3.65 \%$ respectively (Dürr 2019). The species with the least collision risk possibility for the wind park near Hamburg appear to be $M$. daubentonii and $P$. auritus, which is aligned with findings of Dürr (2019) who documented 0,19\% from all of the found carcasses for each of these species.

The controversy over the finding of Dürr (2019) and the data from the literature research for $P$. nathusii, E. serotinus, $P$. pipistrellus and $P$. pygmaeus raise questions about the degree of influence of certain characteristics above others. Do certain wavelengths of light attract some bat species to substantially higher altitudes than they typically use? How will activating obstruction lighting of wind turbines only on need change the found carcass distribution? Are species with frequently found carcasses more represented in the area and what does their frequent killing mean for their population? How to optimize shut down algorithms of wind turbines in order to protect bats? These and other questions are still open and further research is needed. 


\section{References}

Bat Conservation Trust (2008): Noctule bat. Nyctalus noctula. London. Available online at www.bats.org.uk, checked on 3/27/2019.

Brinkmann, Robert; Behr, Oliver; Niermann, Ivo; Reich, Michael (Eds.) (2011):

Entwicklung von Methoden zur Untersuchung und Reduktion des Kollisionsrisikos von Fledermäusen an Onshore-Windenergieanlagen. Göttingen: Cuvillier Verlag (Umwelt und Raum, Bd. 4).

Denzinger, Annette; Schnitzler, Hans-Ulrich (2013): Bat guilds, a concept to classify the highly diverse foraging and echolocation behaviors of microchiropteran bats. In Frontiers in Physiology 4. DOI: 10.3389/fphys.2013.00164.

Deutsche WindGuard GmbH (2019): Status des Windenergieausbaus an Land in Deutschland. Erstes Halbjahr 2019. Available online at https://www.windguard.de/statistik1-halbjahr-2019.html, checked on 8/14/2019.

Dietz, Christian; Kiefer, Andreas (2014): Die Fledermäuse Europas. Kennen, bestimmen, schützen. Stuttgart: Kosmos.

Dürr, Tobias (2019): Fledermausverluste an Windenergieanlagen in Deutschland. Daten aus der zentralen Fundkartei der Staatlichen Vogelschutzwarte. Landesamt für Umwelt Brandenburg. Available online at http://www.lfu.brandenburg.de/cms/detail.php/bb1.c.312579.de, checked on 8/30/2019.

Bundesnaturschutzgesetz, 9/15/2017: Gesetz über Naturschutz und Landschaftspflege.

Herrchen \& Schmitt (2018): L3193 Ausbau - Artenschutzrechtlicher Fachbeitrag. Prüfbögen der anweisen Konfliktanalyse.

Hochradel, Klaus; Adomeit, Uwe; Heinze, Nic; Nagy, Martina; Stiller, Florian; Behr, Oliver (2015): Wärmeoptische 3D-Erfassung von Fledermäusen im Rotorbereich von Windenergieanlagen. In Oliver Behr, Robert Brinkmann, Franzi Korner-Nievergelt, Martina Nagy, Ivo Niermann, Michael Reich, Ralph Simon (Eds.): Reduktion des Kollisionsrisikos von Fledermäusen an Onshore-Windenergieanlagen (RENEBAT II). Umwelt und Raum Bd. 7. Hannover: Schriftenreihe Institut für Umweltplanung, Hannover, pp. 81-100.

Middleton, Neil E. (2006): The speed of travel of Myotis daubentonii along canal corridors in central Scotland. In BaTML Publications 3, pp. 19-22. Available online at www.batml.org.uk. 
Nature Conservation Directive of the European Union: Richtlinie 92/43/EWG des Rates vom 21. Mai 1992 zur Erhaltung der natürlichen Lebensräume sowie der wildlebenden Tiere und Pflanzen. FFH-Richtlinie.

Reimers, Holger (2015): Windpark Curslack Fachbeitrag Fledermäuse. UIN Umweltkartierung- Informationsverarbeitung Umweltbewertung.

Roemer, C.; Disca, T.; Coulon, A.; Bas, Y. (2017): Bat flight height monitored from wind masts predicts mortality risk at wind farms. In Biological Conservation 215, pp. 116-122. DOI: 10.1016/j.biocon.2017.09.002.

Seibert, Anna-Maria; Koblitz, Jens; Denzinger, Annette; Schnitzler, Hans-Ulrich (2013): Scanning Behavior in Echolocating Common Pipistrelle Bats (Pipistrellus pipistrellus). In PLOS ONE 8 (4). DOI: 10.1371/journal.pone.0060752.

Simon, Ralph; Hochradel, Klaus; Mages, Jürgen; Nagy, Martina; Naucke, Andreas; Niermann, Ivo et al. (2015): Methoden akustischer Erfassung der Fledermausaktivität an Windenergieanlagen. In Oliver Behr, Robert Brinkmann, Franzi Korner-Nievergelt, Martina Nagy, Ivo Niermann, Michael Reich, Ralph Simon (Eds.): Reduktion des Kollisionsrisikos von Fledermäusen an Onshore-Windenergieanlagen (RENEBAT II). Umwelt und Raum Bd. 7. Hannover: Schriftenreihe Institut für Umweltplanung, Hannover, pp. 39-80.

Spoelstra, Kamiel; van Grunsven, Roy; Ramakers, Jip; Ferguson, Kim; Raap, Thomas; Donners, Maurice et al. (2017): Response of bats to light with different spectra: light-shy and agile bat presence is affected by white and green, but not red light. In Proceedings of The Roal Society 284. DOI: 10.1098/rspb.2017.0075.

Voigt, Christian; Rehnig, Katharina; Lindecke, Oliver; Petersons, Gunars (2018): Migratory bats are attracted by red light but not by warm-white light: Implications for the protection of nocturnal migrants. In Ecology and evolution, pp. 9353-9361. DOI: 10.1002/ece3.4400. 